\title{
Mapping economic drivers of China's NOx emissions due to energy consumption
}

Shutong $\mathrm{He}^{\mathrm{a}, \mathrm{b}, \mathrm{c}, 1}$

Liangzhen Zhao ${ }^{\mathrm{a}, \mathrm{b}, 1}$

Shihao Ding ${ }^{\mathrm{a}, \mathrm{b}}$

Sai Liang

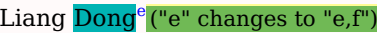

Junfeng Wang $^{\mathrm{a}, \mathrm{b}, *}$

jfwangnk@126.com

Yinchang Fengf ("f" changes to "g")

Lingxuan Liu" ("g" changes to "h")

${ }^{a}$ College of Environmental Science and Engineering, Nankai University, Tianjin, 300500, China

' Research Center for Resource, Energy and Environmental Policy, Nankai University, Tianjin, 300500, China

${ }^{{ }^{\prime} I n s t i t u t e ~ f o r ~ E n v i r o n m e n t a l ~ S t u d i e s ~(I V M), ~ V r i j e ~ U n i v e r s i t e i t ~ A m s t e r d a m, ~} 1081 \mathrm{HV}$, Amsterdam, the Netherlands

${ }^{\mathbf{d}}$ State Key Joint Laboratory of Environment Simulation and Pollution Control, School of Environment, Beijing Normal University, Beijing, 100875, China

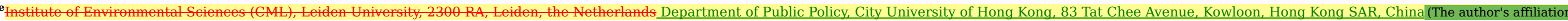
has been changed. Please add another affiliation of this author (Liang Dong): f School of Energy and Environment, City University of Hong Kong, 83 Tat Chee Avenue, Kowloon, Hong Kong SAR, China)

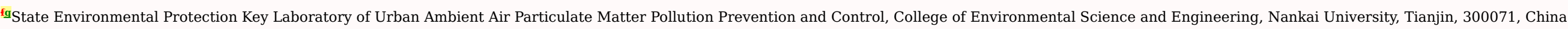

ghManagement School, Lancaster University, LA1 4YX, Bailrigg, Lancashire, United Kingdom

${ }^{*}$ Corresponding author. College of Environmental Science and Engineering, Nankai University, Tianjin, 300500, China.

${ }^{1}$ These authors contributed equally.

Handling Editor: Zhifu Mi

Abstract

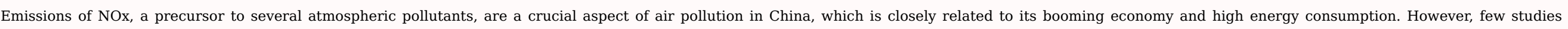

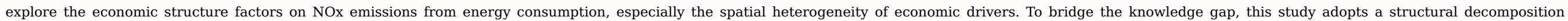

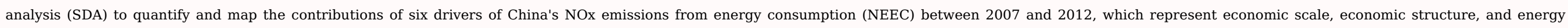

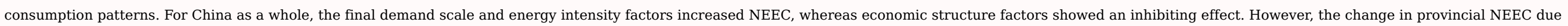

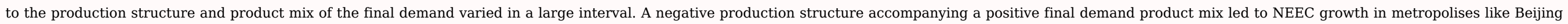

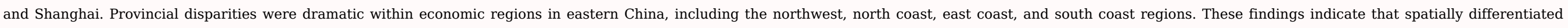

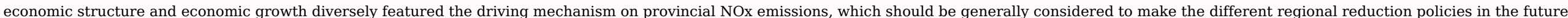


Keywords: NOx emissions; Spatial disparity; Economic drivers; Structural decomposition analysis

\section{Nomenclature}

Abbreviations

NOx

Nitrogen oxides

NEEC

NOx emissions from energy consumption

SDA

Structural decomposition analysis

IDA

Index decomposition analysis

LMDI

Logarithmic Mean Divisia Index

FYP

Five-Year Plan

MIOTs

Monetary input-output tables

ISC

Index of sectoral contribution

Symbols

$\mathrm{Q}$

The calculated NEEC

$\mathrm{N}$

NOx emissions coefficients by sector

Energy intensity, the energy consumption per unit of the total sectoral output

Total output

L 


\section{Introduction}

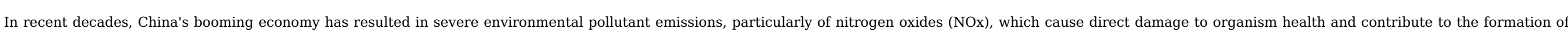

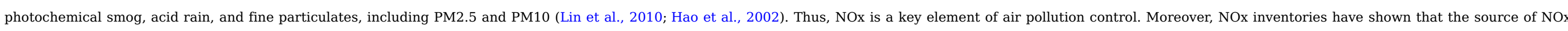

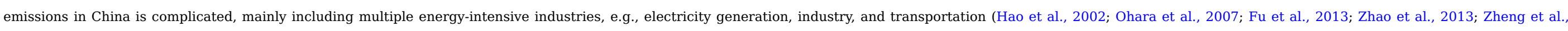

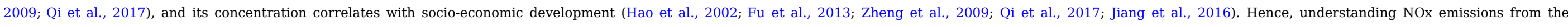
perspective of economic activities, as a complement to the improvement of end-of-pipe treatment, is crucial.

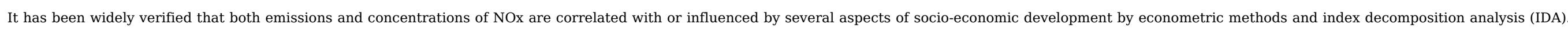

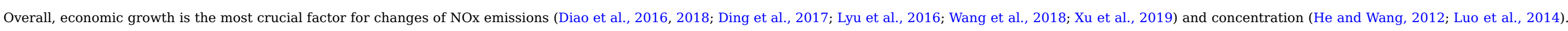

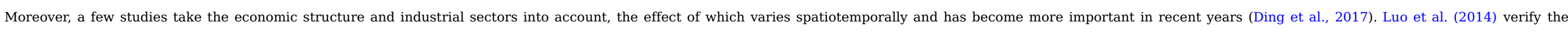

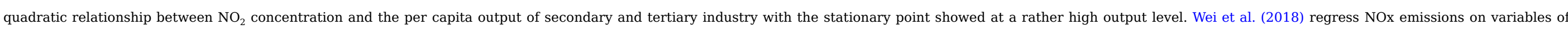

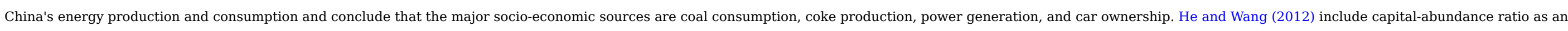

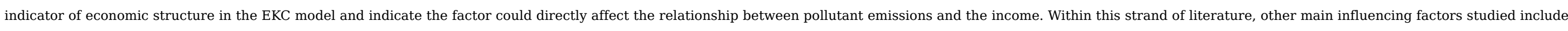

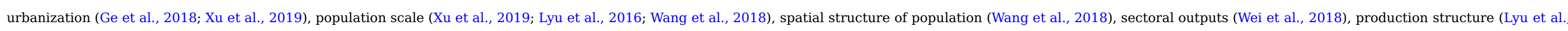
2016), degree of economic openness (He and Wang, 2012), energy efficiency (Xu et al., 2019; Ding et al., 2017; Lyu et al., 2016), and technology improvement (Ding et al., 2017).

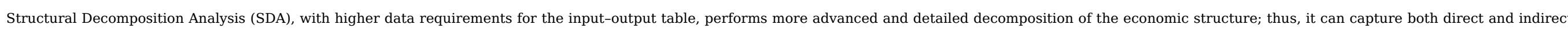

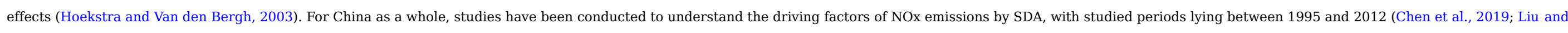

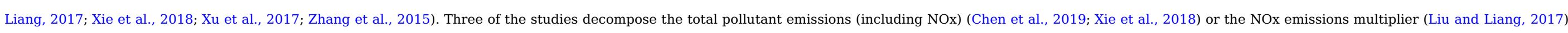

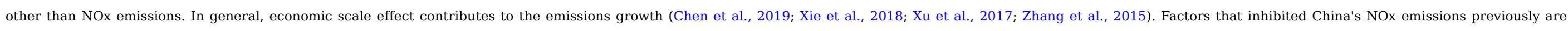

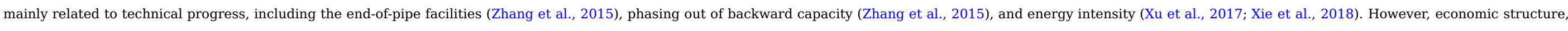
as measured by the change of Leontief inverse matrix, shows varied influences during different periods and among the models (Xu et al., 2017; Zhang et al., 2015; Xie et al., 2018).

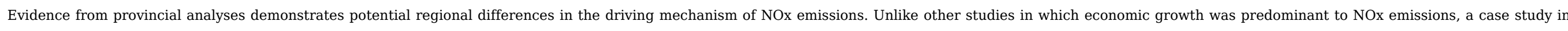

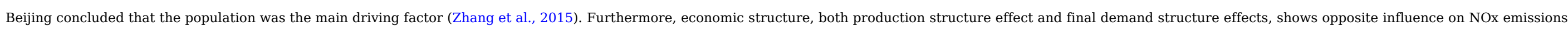
of Beijing and Sichuan (Zhang et al., 2015; Liu et al., 2018).

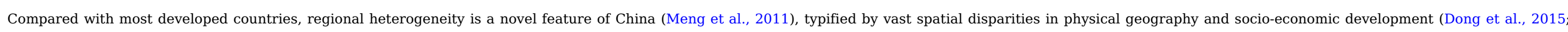




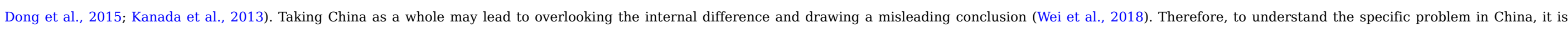
crucial to consider these spatial disparities.

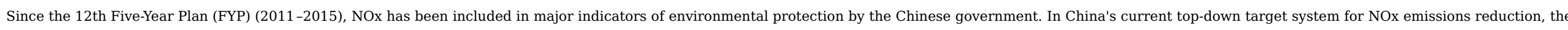

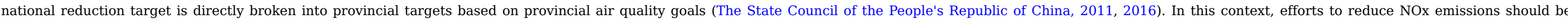

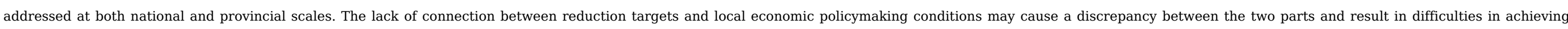
provincial and national reduction targets. To solve this issue, the relationship between NOx emissions and economic development, as well as energy consumption, must first be comprehensively understood.

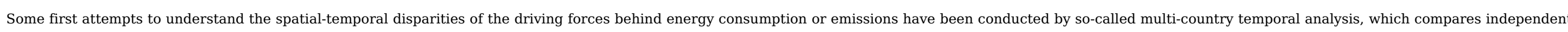

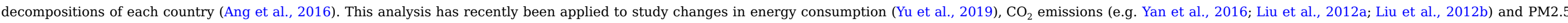

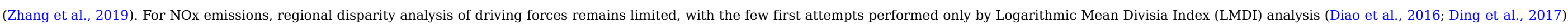

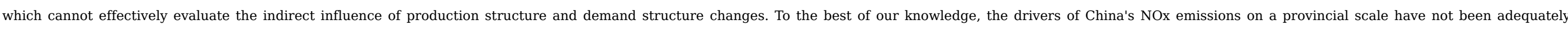
quantified and compared, particularly regarding economic structural factors.

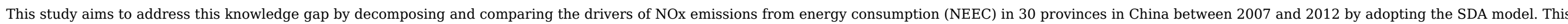

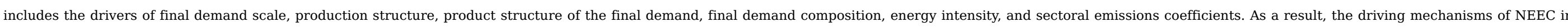

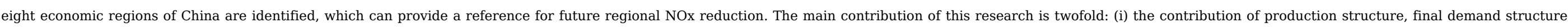

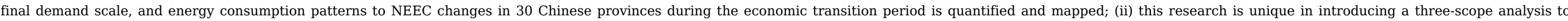
understand the drivers of China's NOx emissions; i.e., national, economic-regional, and provincial analysis, which can help improve the setting of top-down NOx reduction goals in China.

\section{Methods and data}

\subsection{Structural decomposition analysis}

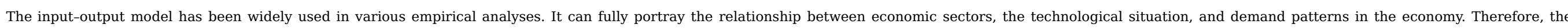

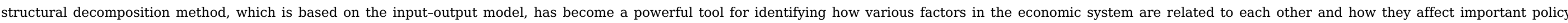

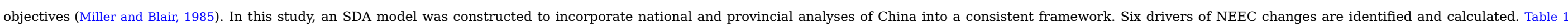
shows a conceptual framework of the environmental-economic input-output model. NEEC can be described and calculated as:

$\mathrm{Q}=\mathrm{NSX}$,

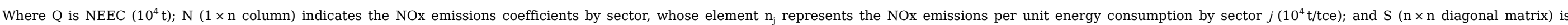

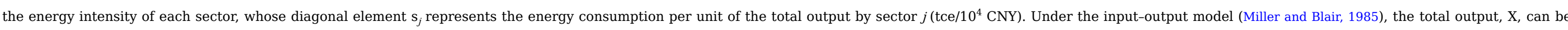
described as:

$X=(I-A)^{-1} Y$

Table 1 Conceptual framework of the environmental-economic input-output model used in this research.

alt-text: Table 1

\begin{tabular}{|c|c|c|c|}
\hline & Intermediate output & Final demand & Total outputs \\
\hline Intermediate input & $A X$ & $Y$ & $X$ \\
\hline Total inputs & $X$ & & \\
\hline NEEC & $N S X$ & & \\
\hline
\end{tabular}

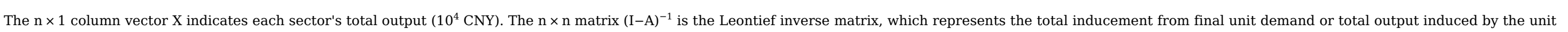




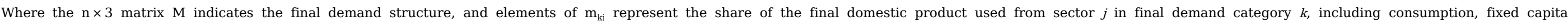

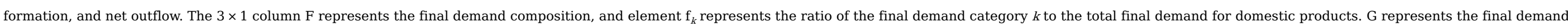
scale $\left(10^{4} \mathrm{CNY}\right)$.

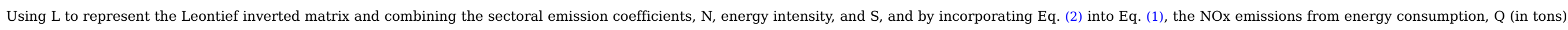
can be described by Eq. (4):

$\mathrm{Q}=\mathrm{NSLMFG}$.

Changes in NEEC through the years can be represented by Eq. (5):

$\Delta Q=Q_{t}-Q_{0}=N_{1} S_{1} L_{1} M_{1} F_{1} G_{1}-N_{0} S_{0} L_{0} M_{0} F_{0} G_{0}$

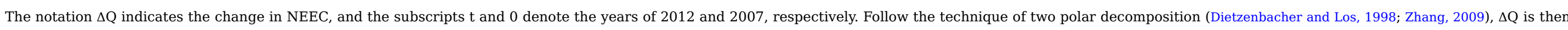
decomposed as shown in Table 2 .

Table 2 Decomposition equation of $\Delta \mathrm{Q}$.

alt-text: Table 2

$$
\begin{aligned}
& =\left(\Delta N \times S_{0} \times L_{0} \times M_{0} \times F_{0} \times G_{0}+\Delta N \times S_{1} \times L_{1} \times M_{1} \times F_{1} \times G_{1}\right) / 2 \\
& +\left(N_{1} \times \Delta S \times L_{0} \times M_{0} \times F_{0} \times G_{0}+N_{O} \times \Delta S \times L_{1} \times M_{1} \times F_{1} \times G_{1}\right) / 2 \\
& +\left(N_{1} \times S_{1} \times \Delta L \times M_{0} \times F_{0} \times G_{0}+N_{O} \times S_{O} \times \Delta L \times M_{1} \times F_{1} \times G_{1}\right) / 2 \\
& +\left(N_{1} \times S_{1} \times L_{1} \times \Delta M \times F_{0} \times G_{0}+N_{0} \times S_{0} \times L_{0} \times \Delta M \times F_{1} \times G_{1}\right) / 2 \\
& +\left(N_{1} \times S_{1} \times L_{1} \times M_{1} \times \Delta F \times G_{0}+N_{0} \times S_{0} \times L_{0} \times M_{0} \times \Delta F \times G_{1}\right) / 2 \\
& +\left(N_{1} \times S_{1} \times L_{1} \times M_{1} \times F_{1} \times \Delta G+N_{0} \times S_{0} \times L_{0} \times M_{0} \times F_{0} \times \Delta G\right) / 2
\end{aligned}
$$

\begin{tabular}{|l|l|}
\hline & $\Delta Q_{N}$ \\
\hline$Q_{S}$ & $\Delta Q_{L}$ \\
\hline & $\Delta Q_{M}$ \\
\hline$Q_{F}$ & $\Delta$ \\
\hline & $\Delta Q_{G}$ \\
\hline
\end{tabular}

Finally, the total change in NEEC can be expressed as:

$$
\Delta Q=\Delta Q_{N}+\Delta Q_{S}+\Delta Q_{L}+\Delta Q_{M}+\Delta Q_{F}+\Delta Q_{G}
$$

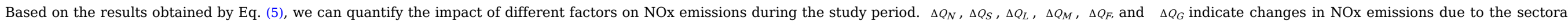
emissions coefficients factor, energy intensity factor, production structure factor, production mix of the final demand factor, final demand composition factor, and final demand scale factor, respectively.

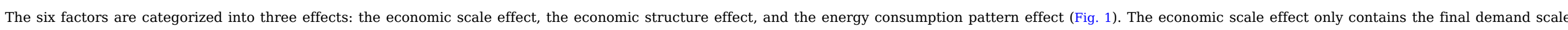

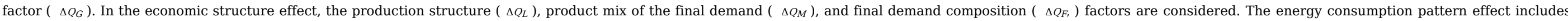

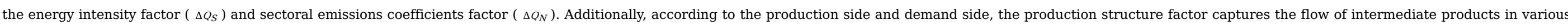
sectors of production. The final demand scale factor, production mix of the final demand factor, and final demand composition factor capture the economic drivers of NEEC from the demand side. 


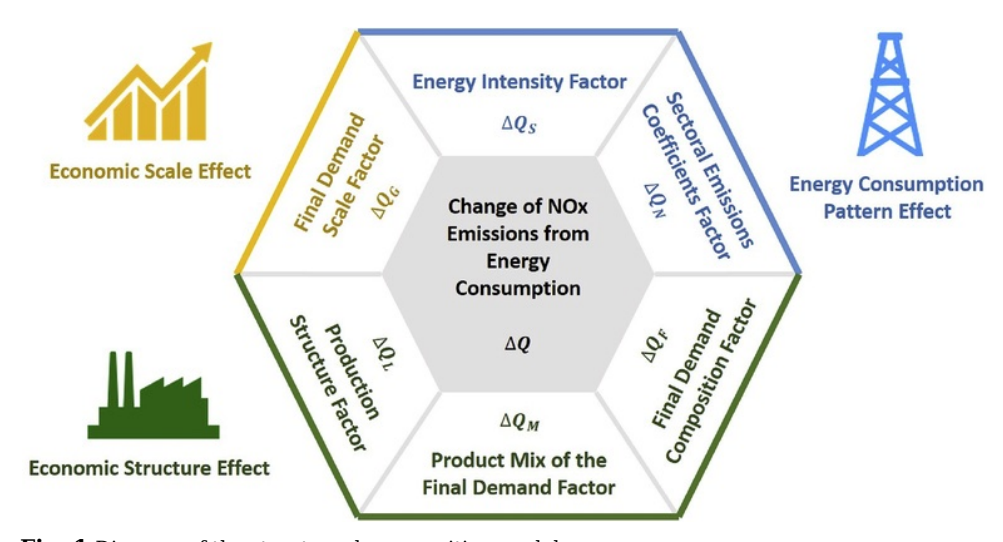

Fig. 1 Diagram of the structure decomposition model.

alt-text: Fig. 1

\subsection{Data source}

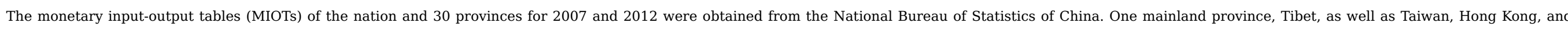

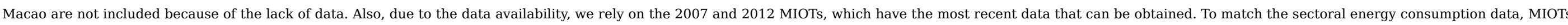

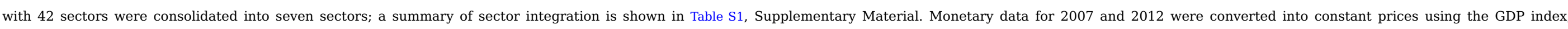

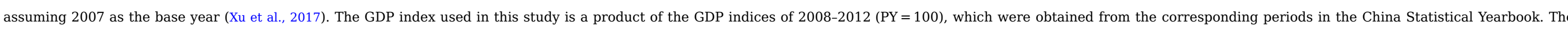

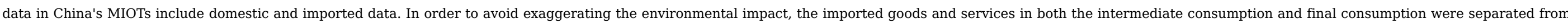

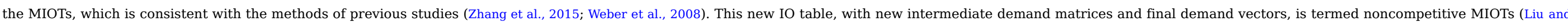

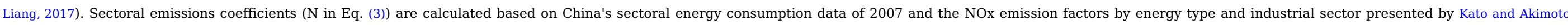

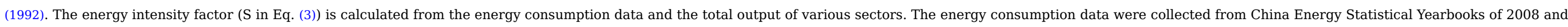
2013.

\section{Results}

\subsection{Overview of NEEC and decomposition results}

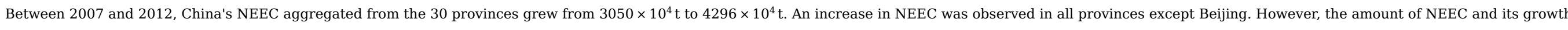

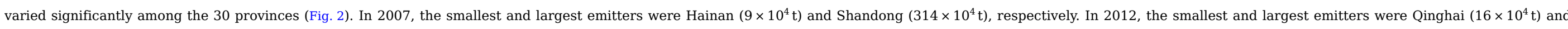

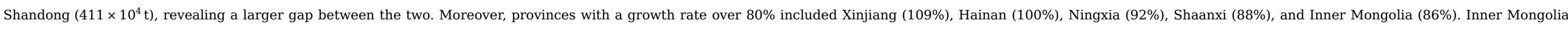

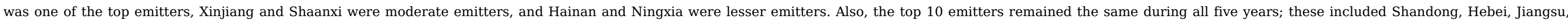
Guangdong, Henan, Inner Mongolia, Liaoning, Zhejiang, Shanxi, and Hubei, which are all eastern coastal provinces and their neighbors. 


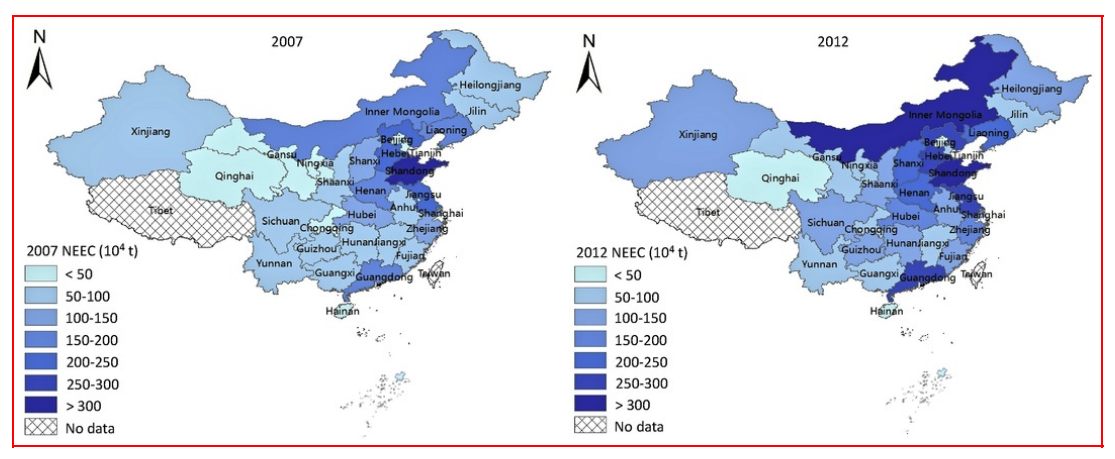

Fig. 2 Geographical distribution of China's NEEC in 2007 and 2012.

alt-text: Fig. 2

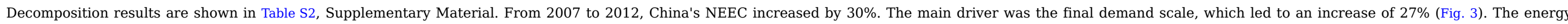

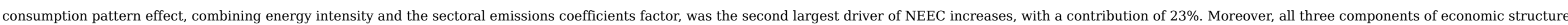

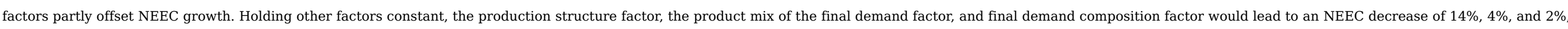
respectively.

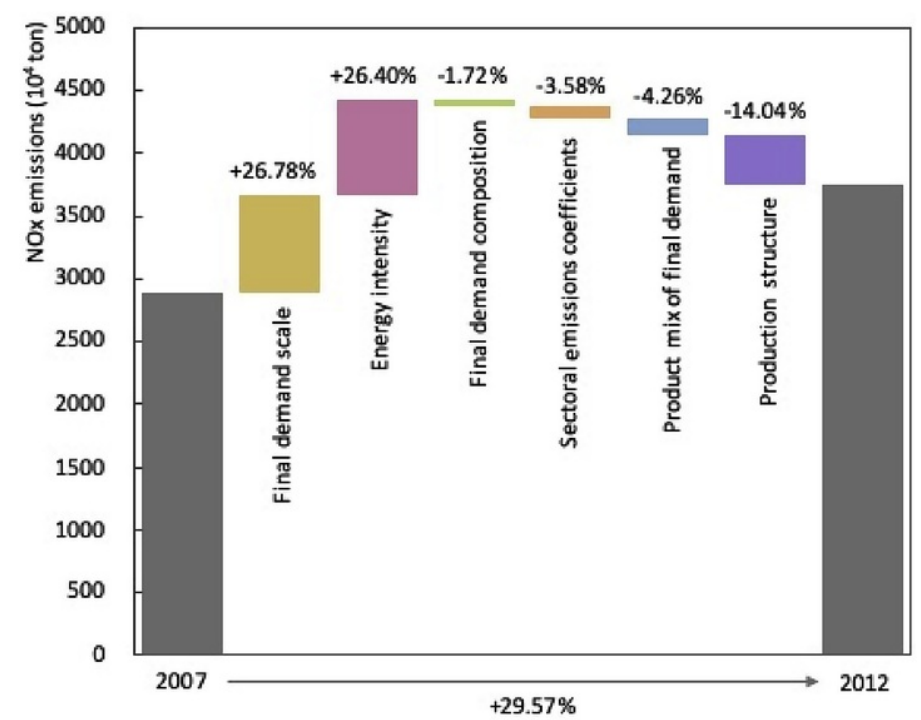

Fig. 3 Contributions of driving factors to national NEEC changes from 2007 to 2012. alt-text: Fig. 3

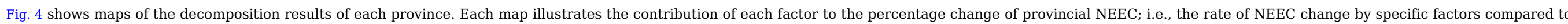

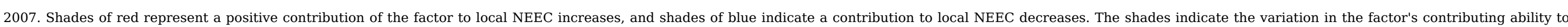

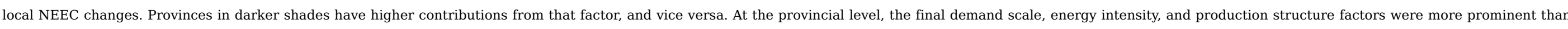

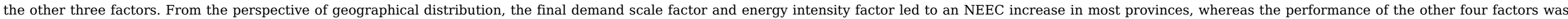
geographically heterogeneous, which is discussed in detail in the following subsections. 


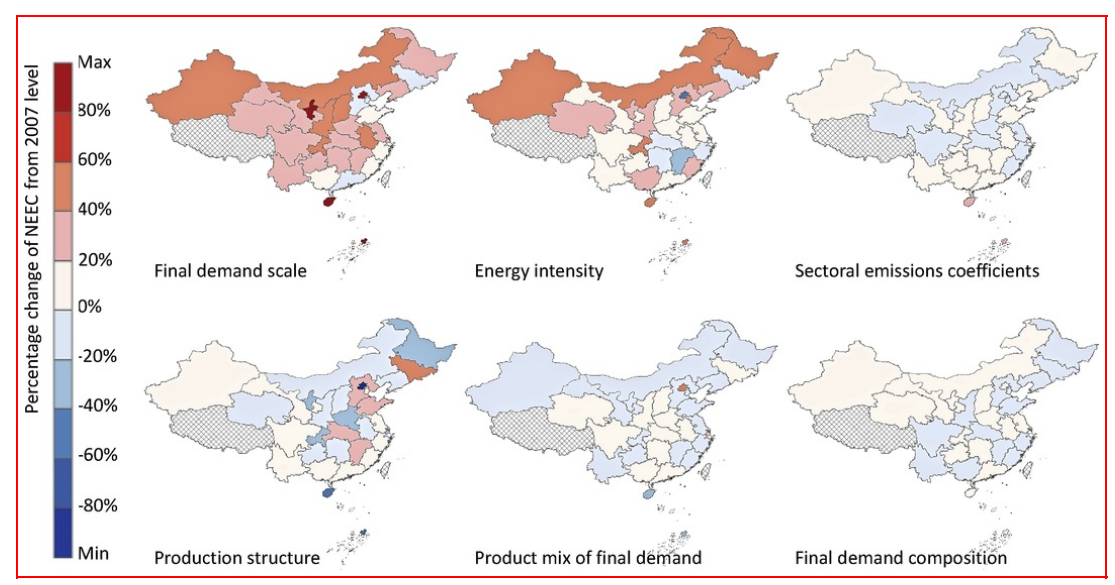

Fig. 4 Contributions of six factors to provincial NEEC changes from 2007 to 2012

alt-text: Fig. 4

3.2 Contribution of the economic scale, economic structure, and energy consumption patterns to national and provincial NEEC changes

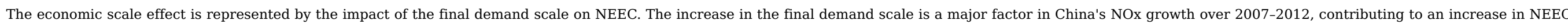

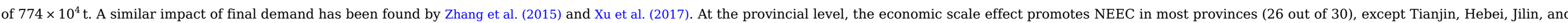

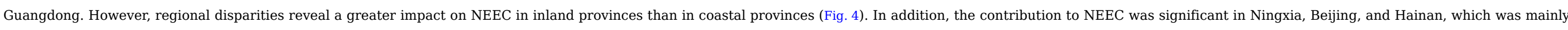
due to their low initial emissions.

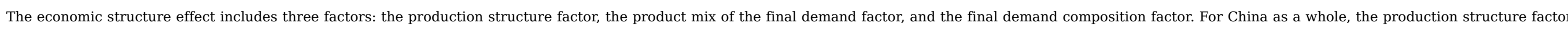

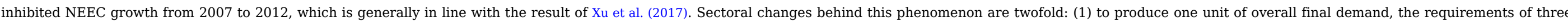

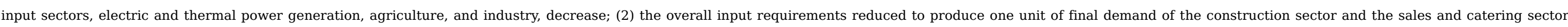

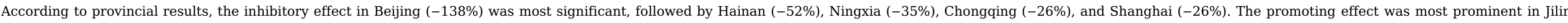
(46\%), followed by Hebei (35\%), Jiangxi (28\%), Hubei (26\%), and Shandong (25\%). The production structure factor inhibited and promoted NEEC to a lesser extent in the other ten provinces.

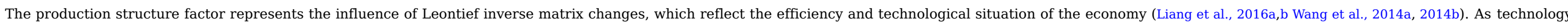

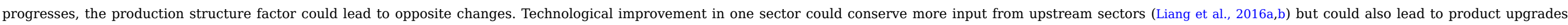

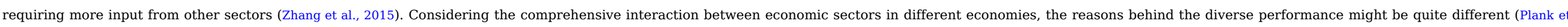

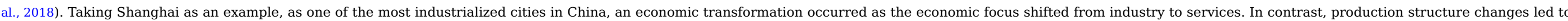
a dramatic increase of NEEC in Hebei and Shandong because the industry remains the leading economic sector during rapid development in these provinces.

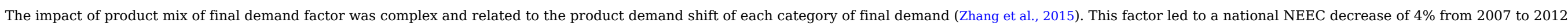

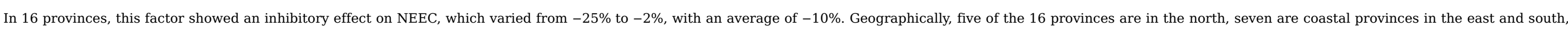

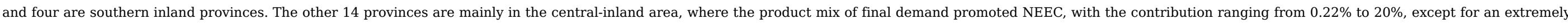
high effect in Beijing (56\%).

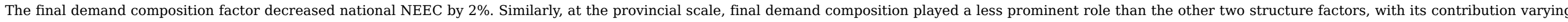

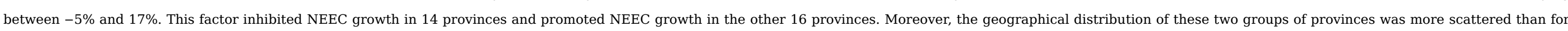




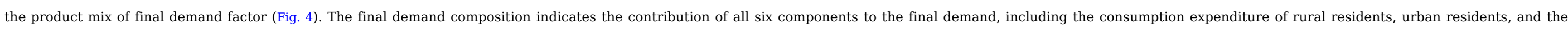

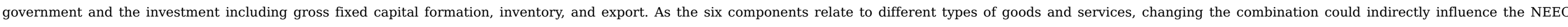

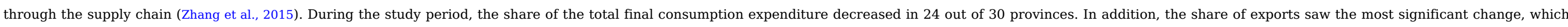

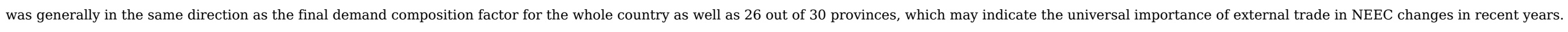

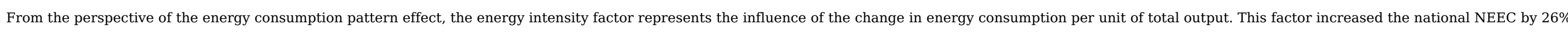

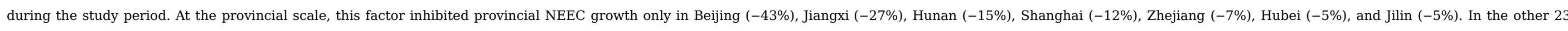

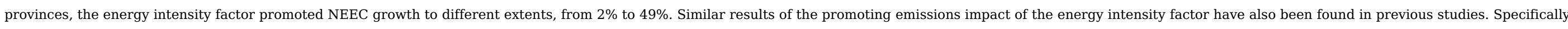

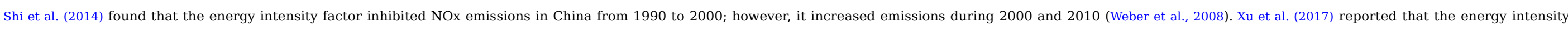

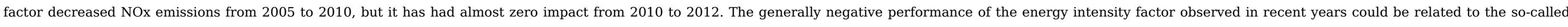
rebound effect, whereby energy efficiency improvements may lead to increased consumption, offsetting the energy saving due to increased efficiency (Baiocchi and Minx, 2010).

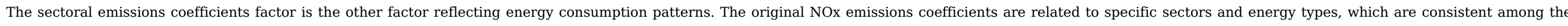

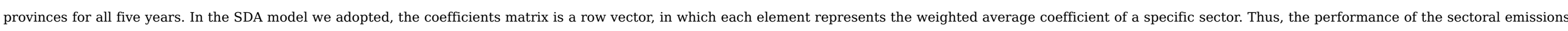

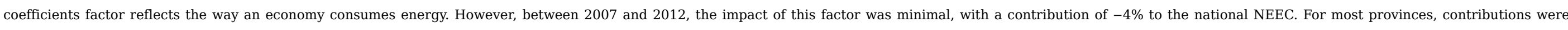
between $-4 \%$ and $12 \%$, except for those of Beijing $(-11 \%)$ and Hainan $(24 \%)$.

\section{Discussion}

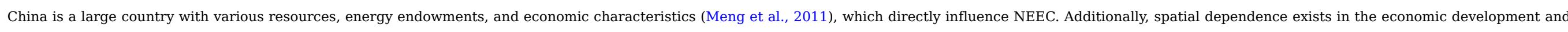

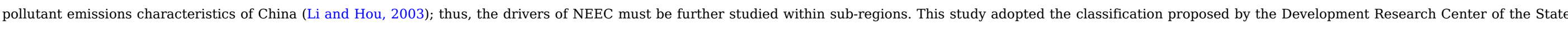

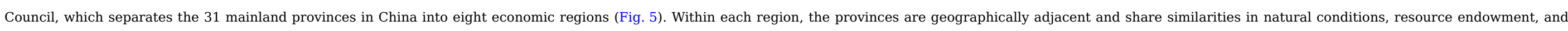
socio-economic characteristics (Li and Hou, 2003).

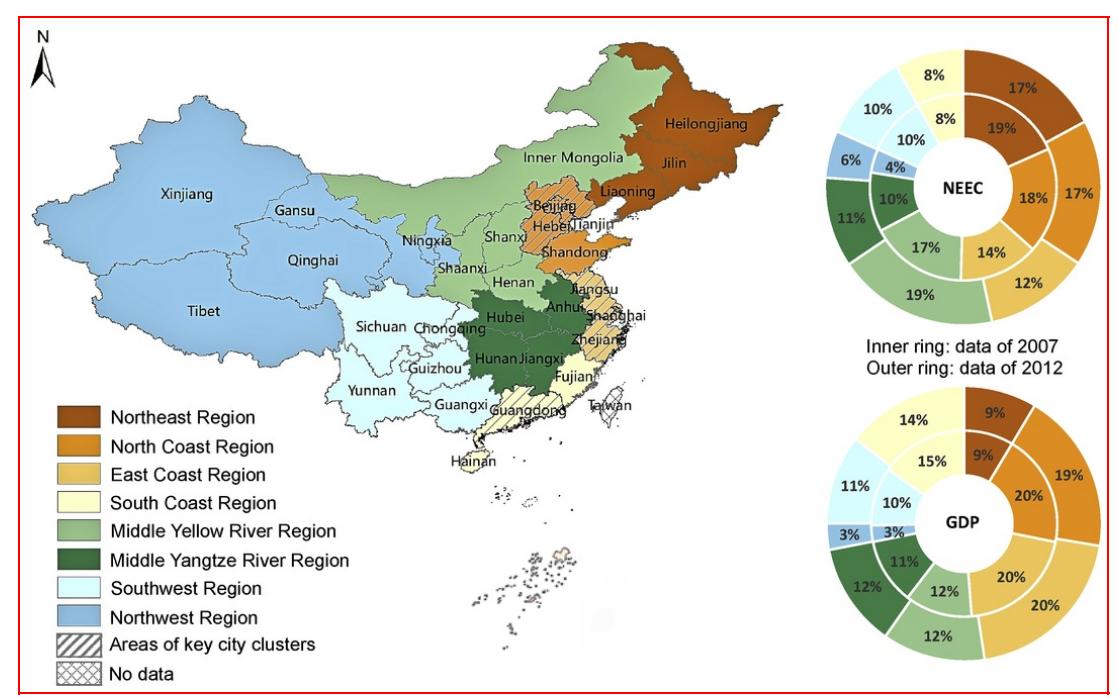

Fig. 5 Geographical distribution, the share of NEEC, and share of GDP for eight economic regions. alt-text: Fig. 5

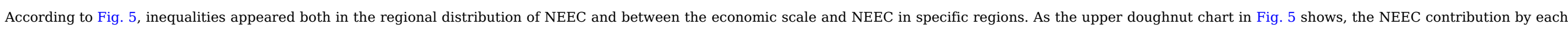




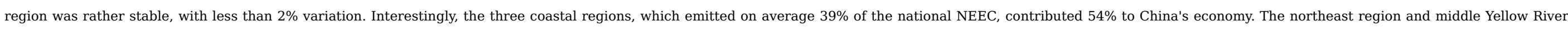
region contributed $21 \%$ to the economy and $36 \%$ of the national NEEC. The other three regions, located in middle and west China, contributed almost equally to the NEEC and GDP.

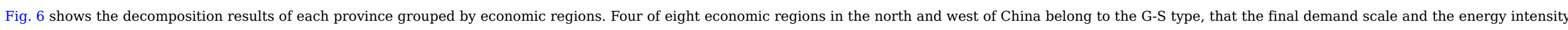

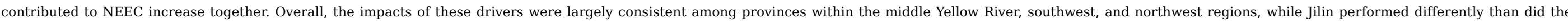

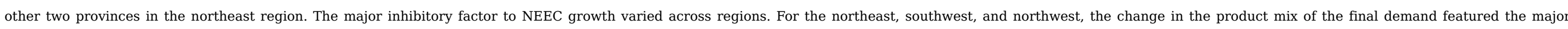
inhibiting factor, whereas the production structure took the place of it in the middle Yellow River region.

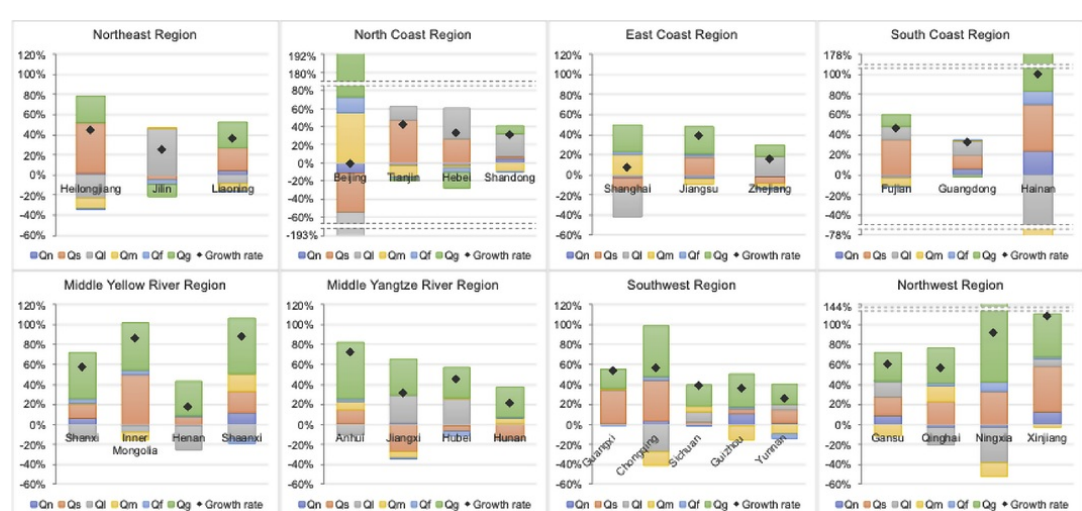

Fig. 6 Contributions of six factors to provincial NEEC changes grouped by region (Y-axis: percentage change of NEEC from 2007 level).

alt-text: Fig. 6

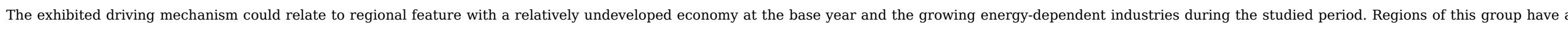

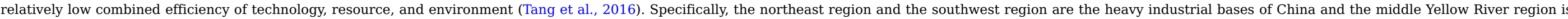

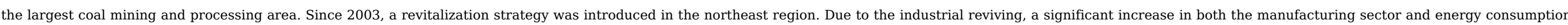

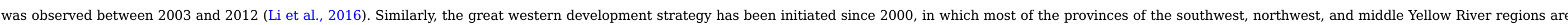
included.

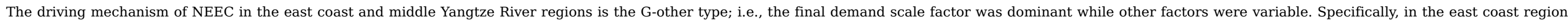

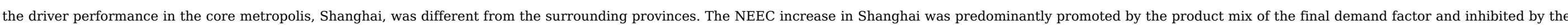

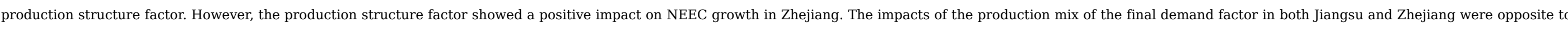

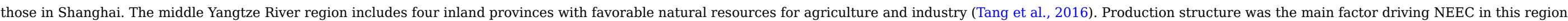
mainly in Jiangxi and Hubei province. The possible reason behind this phenomenon is the growing intermediate input from the power sector and manufacture sector was required to provide the final demand.

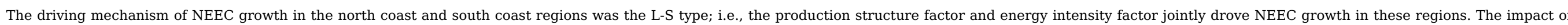

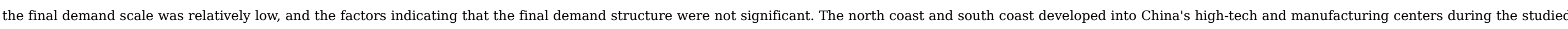
period, while the manufacturing industry of consumer products developed rapidly in the South Coast region.

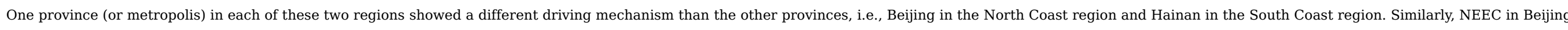

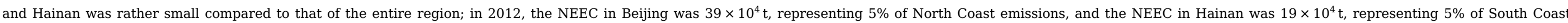

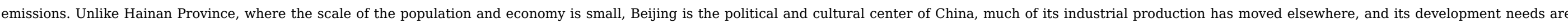
supplied by other provinces, which could indirectly influence the industrial structure, energy consumption, and pollutant emissions in surrounding provinces. 


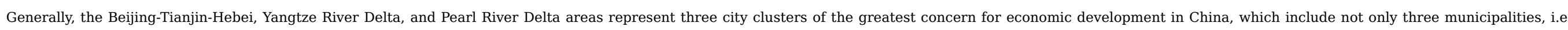

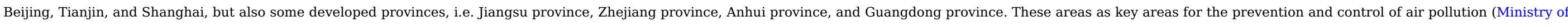

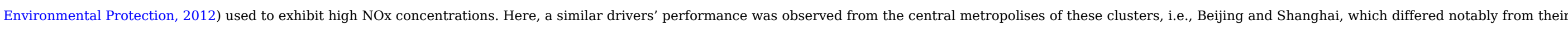

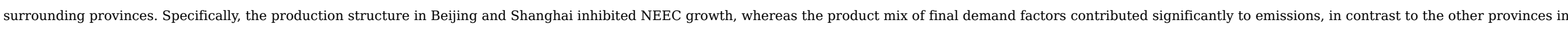

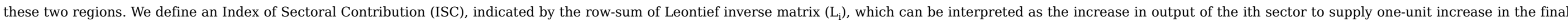

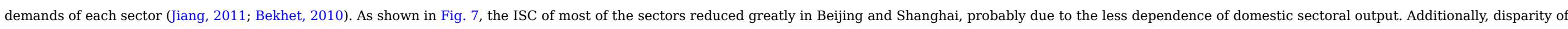
the changes of key sectors within the economic area was more prominent in the Beijing-Tianjin-Hebei area than in the Yangtze River Delta area.

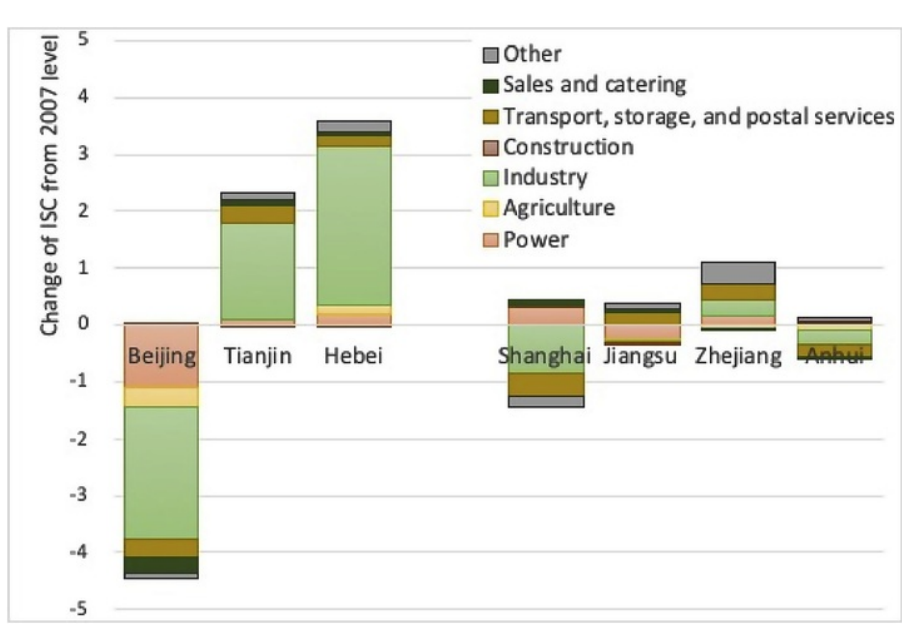

Fig. 7 Change of sectoral intermediate input for one unit of final demand.

alt-text: Fig. 7

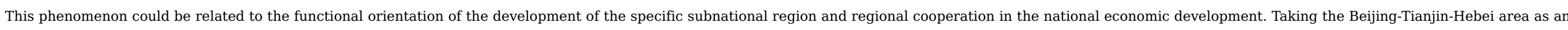

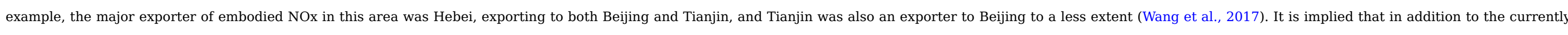

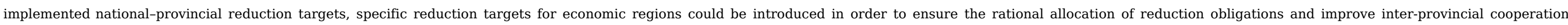
towards overall NOx reductions.

\section{Conclusion}

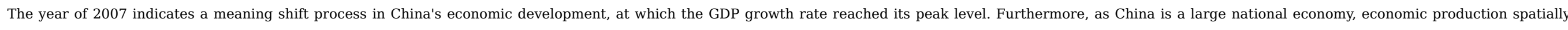

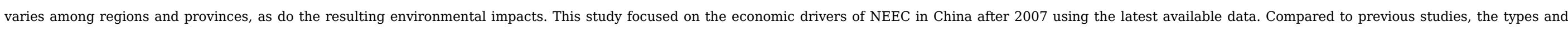
spatial disparities of NEEC driving mechanisms are emphasized. Based on the findings of our research, future NEEC reduction and regional cooperation in China can be better supported.

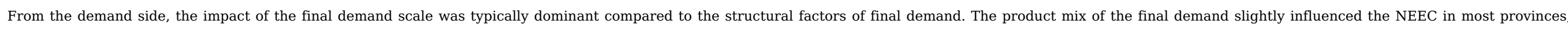

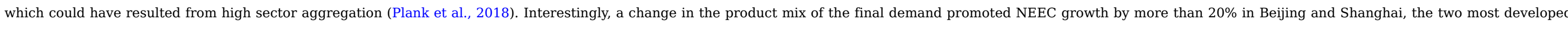

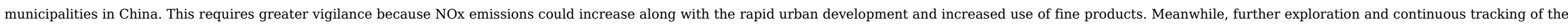
driving mechanism is needed for China's most developed metropolises.

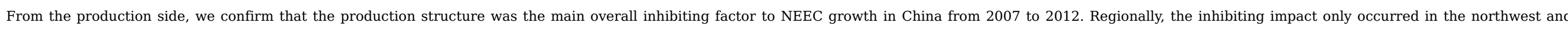

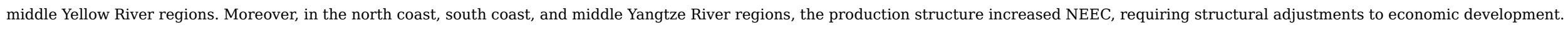




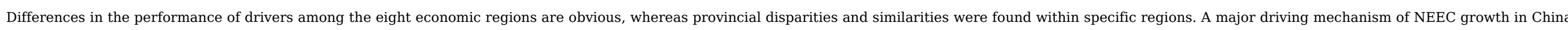

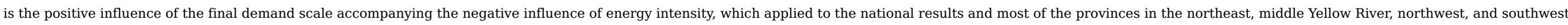
regions. Considering that the economy is expected to grow steadily in the near future in China, promoting energy efficiency and optimizing economic structure could be the main path to NEEC reduction.

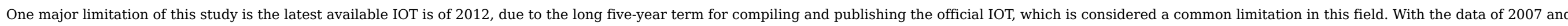

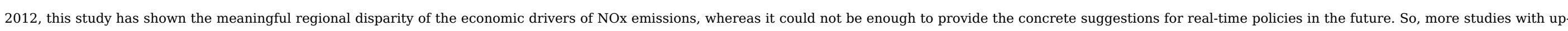

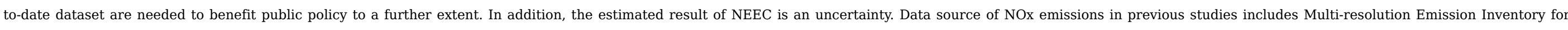

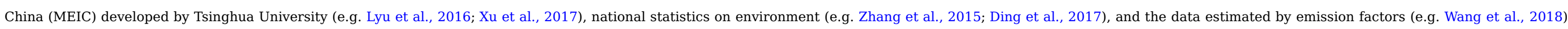

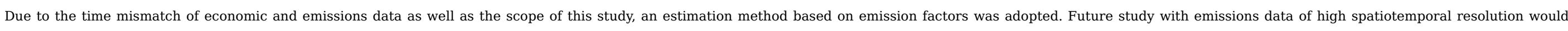
provide a deeper understanding of the driving mechanisms of NOx emissions.

\section{Declarations of interest}

\section{None.}

\section{Acknowledgement}

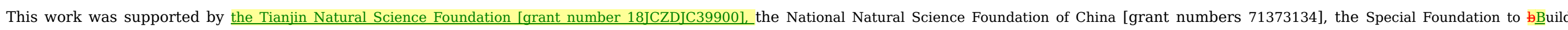

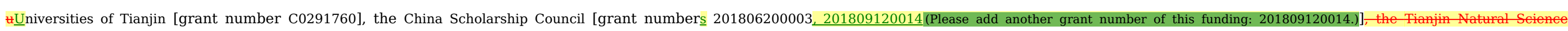
Foundation [grant number 18JCZDJC39900] and the Fundamental Research Funds for the Central Universities.

\section{Appendix A. Supplementary data}

Supplementary data to this article can be found online at https://doi.org/10.1016/j.jclepro.2019.118130.

\section{References}

Ang B.W., Su B. and Wang H., A spatial-temporal decomposition approach to performance assessment in energy and emissions, Energy Econ. 60, $2016,112-121$.

Baiocchi G. and Minx J.C., Understanding changes in the UK's $\mathrm{CO}_{2}$ emissions: a global perspective, Environ. Sci. Technol. 44 (4), 2010, $1177-1184$.

Bekhet H.A., Ranking sectors changes of the Malaysian economy: input-output approach, Int. Bus. Res. 3 (1), 2010, 107.

Chen Y., Li Y. and Yan J., Tracing air pollutant emissions in China: structural decomposition and GVC accounting, Sustainability 11 (9), $2019,2551$.

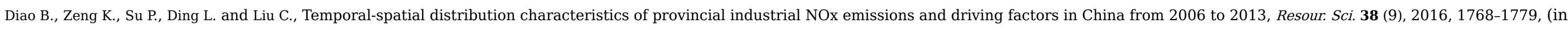
Chinese).

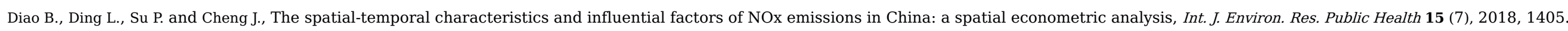

Dietzenbacher E. and Los B., Structural decomposition techniques: sense and sensitivity, Econ. Syst. Res. 10 (4), 1998, 307-324.

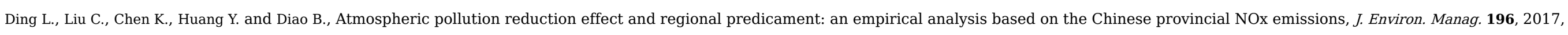

178-187.

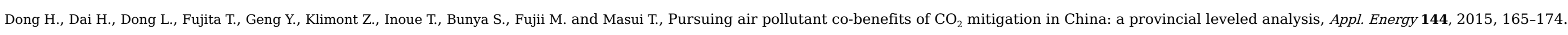

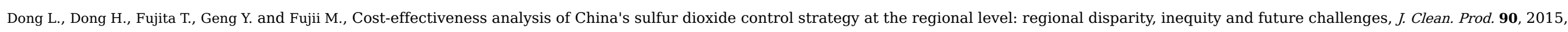

345-359. 


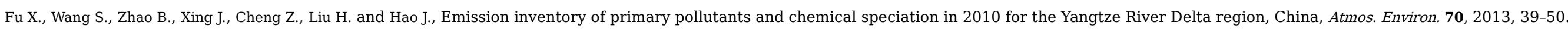
Ge X., Zhou Z., Zhou Y., Ye X. and Liu S., A spatial panel data analysis of economic growth, urbanization, and NOx emissions in China, Int. J. Environ. Res. Public Health 15 (4), $2018,725$.

Hao J., Tian H. and Lu Y., Emission inventories of NOx from commercial energy consumption in China, 1995-1998, Environ. Sci. Technol. 36 (4), 2002, 552-560.

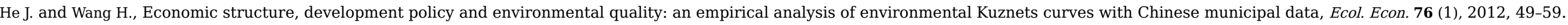

Hoekstra R. and Van den Bergh J.C., Comparing structural decomposition analysis and index, Energy Econ. 25 (1), 2003, 39-64.

Jiang X., Statistical and Economic Applications of Chinese Regional Input-Output Tables, 2011, University of Groningen, SOM research school; Groningen.

Jiang J., Zhang J., Zhang Y., Zhang C. and Tian G., Estimating nitrogen oxides emissions at city scale in China with a nightlight remote sensing model, Sci. Total Environ. 544, 2016, 1119-1127.

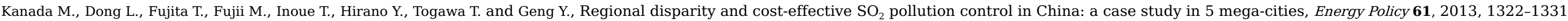

Kato N. and Akimoto H., Anthropogenic emissions of $\mathrm{SO}_{2}$ and NOx in Asia: emission inventories, Atmosp. Environ. Part A. Gen. Topics 26 (16), $1992,2997-3017$.

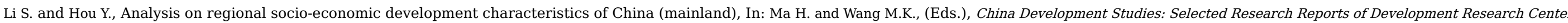
of the State Council (2003 Edition), 2003, China Development Press; Beijing, 244, (In Chinese).

Li H., Lo K., Wang M., Zhang P. and Xue L., Industrial energy consumption in Northeast China under the revitalisation strategy: a decomposition and policy analysis, Energies 9 (7), $2016,549$.

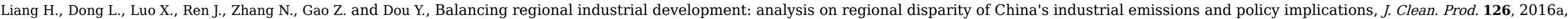
223-235.

Liang S., Wang H., Qu S., Feng T., Guan D., Fang H. and Xu M., Socioeconomic drivers of greenhouse gas emissions in the United States, Environ. Sci. Technol. 50 (14), 2016b, 7535-7545.

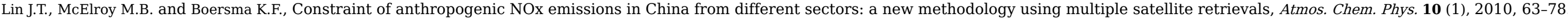
Liu L.J. and Liang Q.M., Changes to pollutants and carbon emission multipliers in China 2007-2012: an input-output structural decomposition analysis, J. Environ. Manag. 203, 2017, 76-86.

Liu Z., Geng Y., Lindner S. and Guan D., Uncovering China's greenhouse gas emission from regional and sectoral perspectives, Energy 45 (1), $2012 \mathrm{a}$, $1059-1068$.

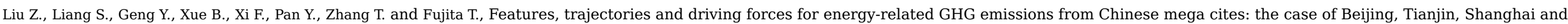
Chongqing, Energy 37 (1), 2012b, 245-254.

Liu L., Chen Y., Wu T. and Li H., The drivers of air pollution in the development of western China: the case of Sichuan province, J. Clean. Prod. 197, 2018, $1169-1176$.

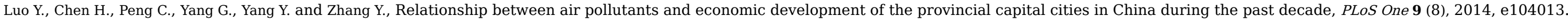

Lyu W., Li Y., Guan D., Zhao H., Zhang Q. and Liu Z., Driving forces of Chinese primary air pollution emissions: an index decomposition analysis, J. Clean. Prod. 133, 2016, 136-144.

Meng L., Guo J.E., Chai J. and Zhang Z., China's regional $\mathrm{CO}_{2}$ emissions: characteristics, inter-regional transfer and emission reduction policies, Energy Policy 39 (10), 2011 , 6136-6144.

Miller R.E. and Blair P.D., Input-output Analysis: Foundations and Extensions, 1985, Cambridge University Press.

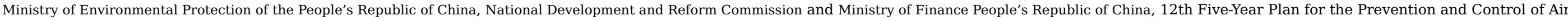
Pollution in Key Areas, 2012, Ministry of Environmental Protection of the People's Republic of China Publishing; China, (In Chinese).

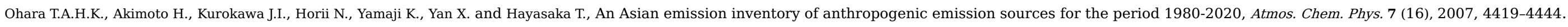

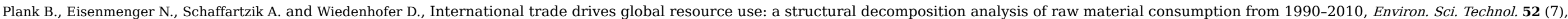


$2018,4190-4198$.

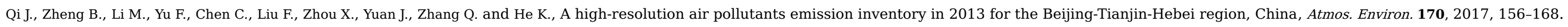
Shi Y., Xia Y., Lu B., Liu N., Zhang L., Li S. and Li W., Emission inventory and trends of NOx for China, 2000-2020, J. Zhejiang Univ. - Sci. 15 (6), 2014 , 454-464, (in Chinese).

Tang K., Yang L. and Zhang J., Estimating the regional total factor efficiency and pollutants' marginal abatement costs in China: a parametric approach, Appl. Energy 184, 2016, 230-240.

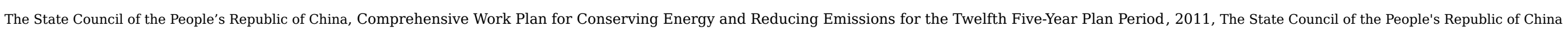
Publishing; China, (In Chinese).

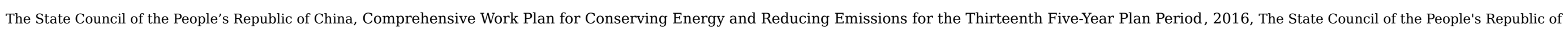
China Publishing; China, (In Chinese).

Wang H., Small M.J. and Dzombak D.A., Factors governing change in water withdrawals for US industrial sectors from 1997 to 2002, Environ. Sci. Technol. 48 (6), 2014a, 3420-3429.

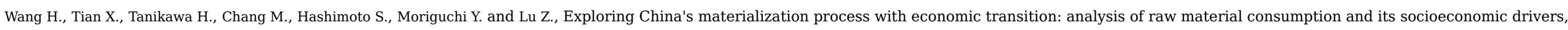
Environ. Sci. Technol. 48 (9), 2014b, 5025-5032.

Wang J., Qiu Y., He S., Liu N., Xiao C. and Liu L., Investigating the driving forces of NOx generation from energy consumption in China, J. Clean. Prod. 184, 2018 , 836-846.

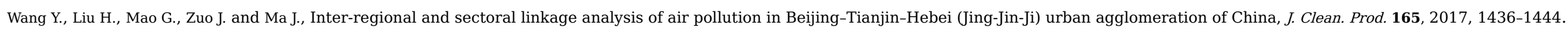

Weber C.L., Peters G.P., Guan D. and Hubacek K., The contribution of Chinese exports to climate change, Energy Policy 36 (9), $2008,3572-3577$.

Wei Y., Gu J., Wang H., Yao T. and Wu Z., Uncovering the culprits of air pollution: evidence from China's economic sectors and regional heterogeneities, J. Clean. Prod. 171, $2018,1481-1493$.

Xie R., Zhao G., Zhu B.Z. and Chevallier J., Examining the factors affecting air pollution emission growth in China, Environ. Model. Assess. 23 (4), $2018,389-400$.

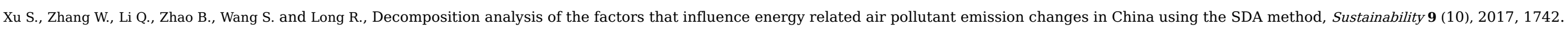

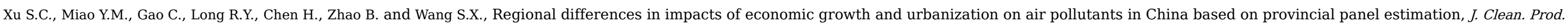

208, 2019, 340-352.

Yan Q., Zhang Q. and Zou X., Decomposition analysis of carbon dioxide emissions in China's regional thermal electricity generation, 2000-2020, Energy 112, 2016, 788-794.

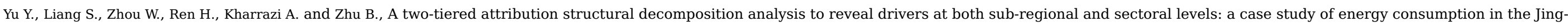
Jin-Ji region, J. Clean. Prod. 213, 2019, 165-175.

Zhang Y., Structural decomposition analysis of sources of decarbonizing economic development in China: 1992-2006, Ecol. Econ. 68 (8-9), $2009,2399-2405$.

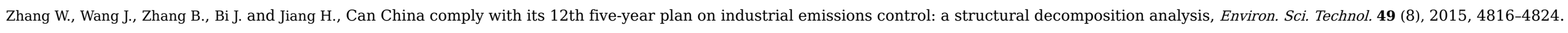

Zhang Y., Wang H., Liang S., Xu M., Zhang Q., Zhao H. and Bi J., A dual strategy for controlling energy consumption and air pollution in China's metropolis of Beijing, Energy 81, $2015,294-303$.

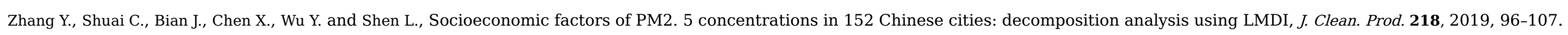

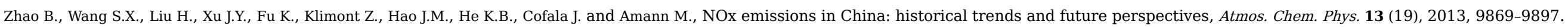

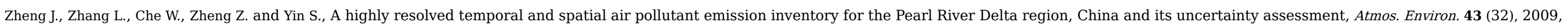

$5112-5122$. 


\section{Appendix A. Supplementary data}

The following is the Supplementary data to this article:

\section{Multimedia Component 1}

Multimedia component 1

alt-text: Multimedia component 1

\section{Graphical abstract}

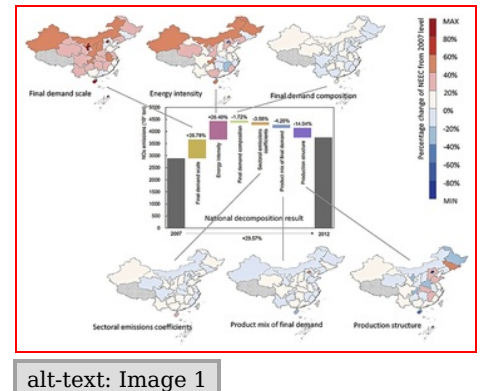

\section{Queries and Answers}

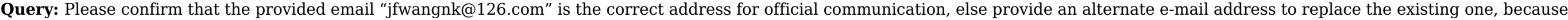
private e-mail addresses should not be used in articles as the address for communication.

Answer: I confirm that the provided email address is correct.

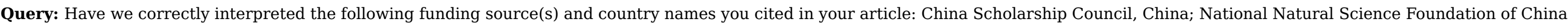
China; Fundamental Research Funds for the Central Universities, China; Tianjin Natural Science Foundation, China; Special Foundation to build universities of Tianjin, China?

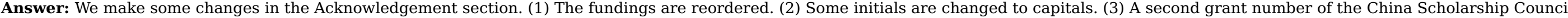
is added.

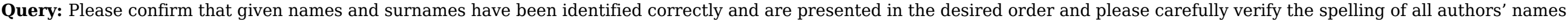

Answer: I confirm that the names of the authors are correct.

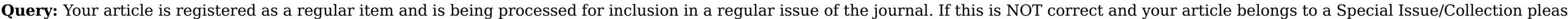
contact k.kumar.1@elsevier.com immediately prior to returning your corrections.

Answer: Yes, this article belongs to a regular issue.

Query: For figure(s) 3,6,7, the resolution is too low to be used. Please provide better quality figure of $300 \mathrm{dpi}$.

Answer: High-resolution files of figures 3, 6, and 7 are attached.

Attachments: Fig 3.pdf, Fig 7.pdf, Fig 6.pdf 